\title{
Doctoral Programs in Mathematics Education: A status report of size, origin of program leadership, and recommended institutions
}

\section{Robert Reys, Barbara Reys, Jeff Shih, and Farshid Safi}

This paper provides a status report on the production of doctorates in mathematics education at institutions across the country. It also reports on where faculty members in active doctoral programs in mathematics education received their doctorates, and it provides a peer-based identification of high quality doctoral programs in mathematics education.

This study uses data gathered from the Survey of Earned Doctorates (SED). The SED began gathering data in 1920 and added mathematics education as a discipline in 1962. The SED is conducted annually and gathers data from every institution in the USA that awards earned doctorates. While the SED has some limitations [1] it provides the most com-

Robert Reys is Curators' Distinguished Professor Emeritus of Mathematics Education at the University of Missouri-Columbia. His email address is ReysR@mi ssouri . edu.

Barbara Reys is Curators' Distinguished Professor Emerita of Mathematics Education at the University of Missouri-Columbia. Her email address is ReysB@missouri . edu.

Jeff Shih is a Professor of Mathematics Education at the University of $\mathrm{Ne}$ vada-Las Vegas. His email is JShih@un7v. nevada.edu.

Farshid Safi is an Assistant Professor of Mathematics Education at the University of Central Florida-Orlando. His email is Farshid.Safi Qucf.edu.

Communicated by Notices Associate Editor William McCallum.

For permission to reprint this article, please contact: reprint -permission@ams.org.

DOI: https://dx.doi.org/10.1090/noti1796 prehensive data available on the production of doctorates in mathematics education.

\section{Production of doctorates in mathematics education over the past three decades}

There were 205 different institutions of higher education that graduated at least one doctorate in mathematics education between 1987 and 2016. The results of the SED survey for the 50 institutions producing the most doctoral graduates in mathematics education are shown in ten-year intervals in Tables 1,2, and 3. The total number of doctoral graduates in mathematics education during these ten-year periods grew from 734 (1987-1996), 928 (1997-2006), and 1428 (2007-2016). These numbers reflect dramatic increases over these periods. One reason for the increases is an effort to address the shortage of doctorates in mathematics education that was reported nearly 20 years ago [ 2 $\& 3]$. Since many job opportunities exist for mathematics educators, institutions have tried to address this need. Additionally, from 2000 to 2003 the National Science Foundation funded several Centers for Learning and Teaching (CLT) that were designed to prepare more doctorates in mathematics (and science) education and that effort prompted an additional bump in the number of graduates.

The data show that the number of doctoral graduates in mathematics education, and the minimum number of doctoral graduates per institution, have increased during each of the ten-year periods. This overall growth of the 


\begin{tabular}{|c|c|c|}
\hline \multicolumn{3}{|c|}{$\begin{array}{l}\text { Table } 1 * \text {. Institutions producing the largest number of doctoral } \\
\text { graduates in mathematics education from } 1987-1996\end{array}$} \\
\hline Rank & Institution & \# of graduates \\
\hline 1 & Teachers College, Columbia University & 70 \\
\hline 2 & University of Georgia & 51 \\
\hline 3 & University of Texas, Austin & 41 \\
\hline 4 & Ohio State University & 34 \\
\hline 5 & Georgia State University & 32 \\
\hline 6 & University of Iowa & 20 \\
\hline \multirow[t]{3}{*}{7} & SUNY, Buffalo & 18 \\
\hline & Rutgers University & 18 \\
\hline & University of Pittsburgh & 18 \\
\hline \multirow[t]{3}{*}{10} & New York University & 17 \\
\hline & American University & 17 \\
\hline & University of Maryland & 17 \\
\hline \multirow[t]{2}{*}{13} & Florida State University & 16 \\
\hline & Temple University & 16 \\
\hline \multirow[t]{2}{*}{15} & Indiana University & 14 \\
\hline & University of Oklahoma & 14 \\
\hline 17 & Boston University & 13 \\
\hline 18 & University of Wisconsin & 12 \\
\hline \multirow[t]{3}{*}{19} & North Carolina State University & 11 \\
\hline & University of Massachusetts Amherst & 11 \\
\hline & Vanderbilt University & 11 \\
\hline 22 & Syracuse University & 10 \\
\hline \multirow[t]{4}{*}{23} & University of Illinois, Urbana-Champaign & 9 \\
\hline & Oregon State University & 9 \\
\hline & University of South Carolina & 9 \\
\hline & University of Tennessee & 9 \\
\hline \multirow[t]{3}{*}{27} & University of Minnesota & 8 \\
\hline & Cornell University & 8 \\
\hline & University of California, Berkeley & 8 \\
\hline \multirow[t]{2}{*}{30} & University of Southern Illinois & 7 \\
\hline & University of South Florida & 7 \\
\hline \multirow[t]{6}{*}{32} & Purdue University & 6 \\
\hline & Illinois State University & 6 \\
\hline & University of Massachusetts-Lowell & 6 \\
\hline & University of Missouri, Columbia & 6 \\
\hline & University of Northern Colorado & 6 \\
\hline & University of Virginia & 6 \\
\hline \multirow[t]{7}{*}{38} & Auburn University & 5 \\
\hline & Texas A \& M University & 5 \\
\hline & University of Michigan & 5 \\
\hline & Michigan State University & 5 \\
\hline & University of Florida & 5 \\
\hline & Oklahoma State University & 5 \\
\hline & University of Alabama & 5 \\
\hline \multirow[t]{3}{*}{45} & Washington State University & 4 \\
\hline & Montana State University & 4 \\
\hline & University of Houston & 4 \\
\hline 48 & Eleven** institutions graduated 3 doctorates & 3 \\
\hline
\end{tabular}

*Institutions in bold appear in Tables 1, 2, and 3.

**University of Chicago, Stanford University, Penn State University, University of Delaware, University of Mississippi, Ohio University, University of Toledo, University of Denver, University of North Carolina, Greensboro, Claremont Graduate School, Kent State University

\begin{tabular}{|c|c|c|}
\hline Rank & Institution & \# of graduates \\
\hline 1 & Teachers College, Columbia University & 74 \\
\hline 2 & University of Georgia & 49 \\
\hline 3 & University of Texas, Austin & 40 \\
\hline 4 & Illinois State University & 38 \\
\hline 5 & North Carolina State University & 29 \\
\hline 6 & Florida State University & 27 \\
\hline 7 & Ohio State University & 25 \\
\hline 8 & Rutgers University & 23 \\
\hline \multirow[t]{2}{*}{9} & Georgia State University & 22 \\
\hline & University of Oklahoma & 22 \\
\hline 11 & American University & 21 \\
\hline 12 & University of Maryland & 20 \\
\hline 13 & Oregon State University & 18 \\
\hline 14 & University of Northern Colorado & 17 \\
\hline 15 & Temple University & 15 \\
\hline \multirow[t]{2}{*}{16} & Indiana University & 14 \\
\hline & University of Missouri, Columbia & 14 \\
\hline \multirow[t]{2}{*}{18} & University of Minnesota & 13 \\
\hline & University of Wisconsin & 13 \\
\hline \multirow[t]{3}{*}{20} & Ohio University & 12 \\
\hline & SUNY, Buffalo & 12 \\
\hline & Vanderbilt University & 12 \\
\hline \multirow[t]{3}{*}{23} & Syracuse University & 11 \\
\hline & University of South Florida & 11 \\
\hline & University of Virginia & 11 \\
\hline \multirow[t]{3}{*}{26} & Auburn University & 10 \\
\hline & Michigan State University & 10 \\
\hline & University of California, Berkeley & 10 \\
\hline \multirow[t]{4}{*}{29} & University of Illinois, Urbana-Champaign & 9 \\
\hline & University of Iowa & 9 \\
\hline & University of Massachusetts, Lowell & 9 \\
\hline & University of Pittsburgh & 9 \\
\hline \multirow[t]{4}{*}{33} & Boston University & 8 \\
\hline & University of Michigan & 8 \\
\hline & University of South Carolina & 8 \\
\hline & University of Tennessee & 8 \\
\hline \multirow[t]{4}{*}{37} & Penn State University & 7 \\
\hline & University of Arizona & 7 \\
\hline & University of New Hampshire & 7 \\
\hline & Western Michigan University & 7 \\
\hline \multirow[t]{7}{*}{41} & Montana State University & 6 \\
\hline & Montclair State University & 6 \\
\hline & New York University & 6 \\
\hline & University of Central Florida & 6 \\
\hline & University of Houston & 6 \\
\hline & University of Kansas & 6 \\
\hline & University of Massachusetts, Amherst & 6 \\
\hline 48 & Eight $* *$ institutions graduated 5 doctorates & 5 \\
\hline
\end{tabular}

* * Claremont Graduate University, San Diego State University-University of California, San Diego (SDSU-UCSD), University of Alabama, University of Arizona, University of California-Davis, University of Chicago, University of Delaware, University of Southern Mississippi 


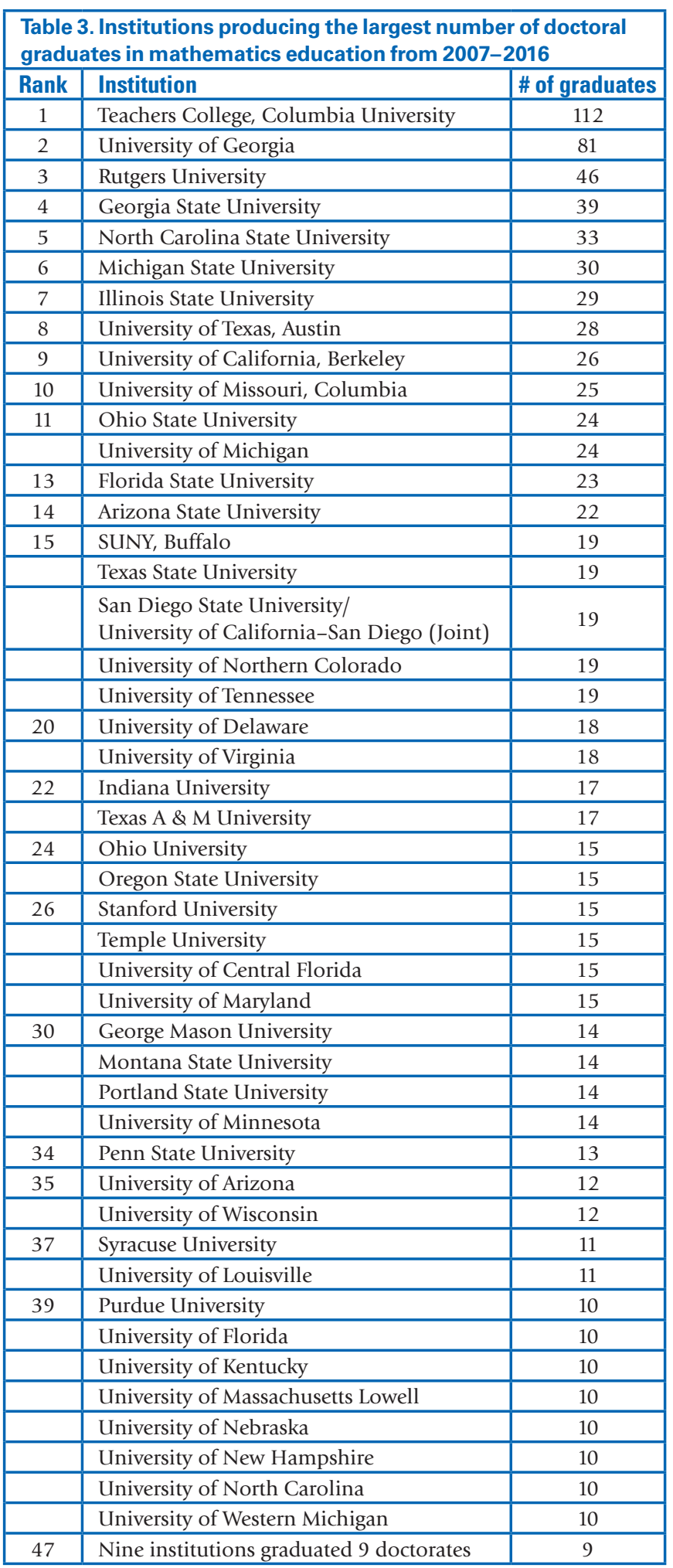

**Illinois Institute of Technology, Kansas State University, Middle Tennessee State University, University of California-Davis, University of Illinois, Urbana-Champaign, University of Oklahoma, University of South Florida, University of Southern Mississippi, Utah State University number of doctoral graduates in mathematics education was reported earlier in some detail [4]. In addition to the increasing number of graduates, an examination of Tables 1,2 , and 3 shows a number of patterns. The Teachers College and the University of Georgia graduated by far the most doctorates in mathematics education during each time period. Georgia State University, Rutgers University, and the University of Texas were the only other institutions to be included in the top ten producers of doctoral graduates during each ten-year period. While there is some shuffling in the order of the largest producers during these three time periods, 32 institutions appear in each of the three tables, and these institutions are shown in bold in Table 1.

Most doctoral programs in mathematics education in institutions shown in Tables 1, 2, and 3 are offered in the college/school of education. However, some institutions house the doctoral program in mathematics education in the mathematics department, including Arizona State University, Illinois State University, Montclair State University, Portland State University, University of New Hampshire, University of Northern Colorado, Texas State University, and Western Michigan University. Other institutions, such as Michigan State University, Oklahoma State University, Oregon State University, Syracuse University, University of Nebraska, University of South Carolina, and the University of Arizona, offer a doctorate in mathematics education in both the mathematics department and in the college/ school of education.

Tables 2 and 3 show that several institutions, such as Michigan State University and University of California-Berkeley more than doubled their production in PhDs in mathematics education. More than one-half the institutions in Table 2 showed a growth in the number of doctoral graduates compared to Table 3. Two institutions, Arizona State University and Texas State University, appeared for the first time in Table 3. Notably, these two programs, together with the joint program at SDSU/UCSD, did not appear among the top producers in the earlier period covered by Table 1. Two institutions that appear in Table 1 and 2, the University of Chicago and American University, closed their doctoral programs and so do not appear in Table 3. It is worth noting that the doctoral program in mathematics education at University of Chicago was over 100 years old. It was a highly respected program and was the second oldest doctoral program in mathematics education in the United States, second only to Teachers College, Columbia University [5].

\section{Where faculty producing future mathematics educators earned their doctorate}

This is an important factor because the academic preparation of faculty members involved in doctoral programs impacts the curriculum of the program; it may influence the research experiences, as well as admission procedures, 
advisement, comprehensive exams, dissertations, and follow-up of doctoral graduates. Furthermore, institutions hiring new faculty may want to hire people with doctorates from certain institutions to strengthen their programs. They may be seeking new faculty members with certain kinds of knowledge or research expertise, or who have studied with specific people who are nationally recognized, or who have graduated from highly respected institutions. Information about where people earned their doctorate as well as the faculty who implemented the programs can be useful. To obtain these data, we developed and facilitated a survey.

Survey participants were faculty members in doctoral programs in mathematics education. The targeted institutions had graduated at least ten doctorates in mathematics education during the last 20 years and had produced at least one graduate in the last five years. These parameters generated a list of 64 different institutions. These 64 institutions have graduated 2249 doctorates in mathematics education during the 30-year period (1987-2016), or about 73\% of all of the people receiving a doctorate in mathematics education during that time period. Consequently, these 64 institutions represent a major pipeline of producers of doctorates in mathematics education. A faculty member at

\begin{tabular}{|c|c|c|}
\hline \multicolumn{3}{|c|}{$\begin{array}{l}\text { Table 4. The top } 20 \text { institutions producing faculty members in } \\
\text { doctoral programs in mathematics education in institutions } \\
\text { graduating the most doctorates in mathematics education }\end{array}$} \\
\hline Rank & Institution & $\begin{array}{c}\text { \# of doctoral graduates } \\
\text { from these institutions } \\
\text { contributing to } \\
\text { doctoral programs }\end{array}$ \\
\hline 1 & University of Georgia & 21 \\
\hline 2 & Michigan State University & 16 \\
\hline 3 & University of California, Berkeley & 12 \\
\hline 4 & University of Wisconsin & 11 \\
\hline 5 & $\begin{array}{l}\text { San Diego State University \& } \\
\text { University of California, San Diego } \\
\text { (Joint SDSU-UCSD) }\end{array}$ & 10 \\
\hline 6 & University of Texas & 9 \\
\hline 7 & Illinois State University & 9 \\
\hline \multirow[t]{3}{*}{8} & Indiana University & 8 \\
\hline & Ohio State University & 8 \\
\hline & Stanford University & 8 \\
\hline \multirow[t]{2}{*}{11} & University of Maryland, College Park & 7 \\
\hline & University of Michigan & 7 \\
\hline \multirow[t]{3}{*}{13} & Harvard University & 6 \\
\hline & Penn State University & 6 \\
\hline & Rutgers University & 6 \\
\hline \multirow[t]{7}{*}{16} & Northwestern University & 5 \\
\hline & Teachers College, Columbia University & 5 \\
\hline & University of Central Florida & 5 \\
\hline & University of Minnesota & 5 \\
\hline & University of Missouri & 5 \\
\hline & Vanderbilt University & 5 \\
\hline & TOTAL: & 174 \\
\hline
\end{tabular}

each institution was contacted and asked to identify all of the faculty members (such as mathematics educators and mathematicians) that were actively involved in their doctoral program in mathematics education. Part-time adjunct appointments and retired faculty were not included. A list of 297 faculty members were identified, and 266 (almost $90 \%$ ) responded to the survey. One of them did not hold an earned doctoral degree and nine of them earned a doctorate from an international institution. Therefore, data from 256 faculty members served as the basis for analysis.

Surveyed faculty were asked to identify the institution where they earned their doctorate. Table 4 identifies the 21 institutions that produced the largest number of faculty members currently working in doctoral programs in mathematics education. Table 4 shows that 174 of the 256 faculty members surveyed (69\%) earned their doctorate at one of these 21 institutions.

An examination of Table 4 shows that the University of Georgia is the institution graduating the most people currently serving as faculty in doctoral programs in mathematics education. Although Teachers College, Columbia University appears in Table 4, given the large number of graduates Teachers College has produced, it is surprising that their graduates were not often found among the faculty of doctoral programs in these institutions.

\section{Institutions recommended by faculty to potential doctoral students in mathematics education}

Specific information about doctoral programs in mathematics education is helpful to potential doctoral students seeking a program. Recommendations from faculty can also be beneficial in shortening a list of possible institutions to consider. Each faculty member in the survey was presented this question:
Suppose you were asked by a potential doctoral student in mathematics education to iden- tify "particularly strong doctoral programs" (regardless of location or areas of interest) to consider attending. Which institutions would you recommend?

Surveyed faculty were allowed to name up to 8 institutions, and told it was not necessary to order the institutions. They were also asked not to name the institution where they were currently employed. Some faculty members identified eight institutions, some only a couple.

More than 260 of the faculty members responded, but a few of them did not name any institution. In such cases, they said their recommendation of an institution would depend on the interest of the doctoral student and the specialty or niches found at specific institutions. One faculty member indicated he/she would not recommend an institution, but rather seek to match the research interest 
of the potential doctoral student with a particular scholar independent of an institution.

A total of 94 different institutions were recommended, including 6 institutions in other countries. No institution was recommended by every faculty member, but three institutions (University of Georgia, Michigan State University, and the University of Michigan) were named by more than one-half of the faculty members. A list of all the institutions recommended by more than ten faculty members is shown in Table 5.

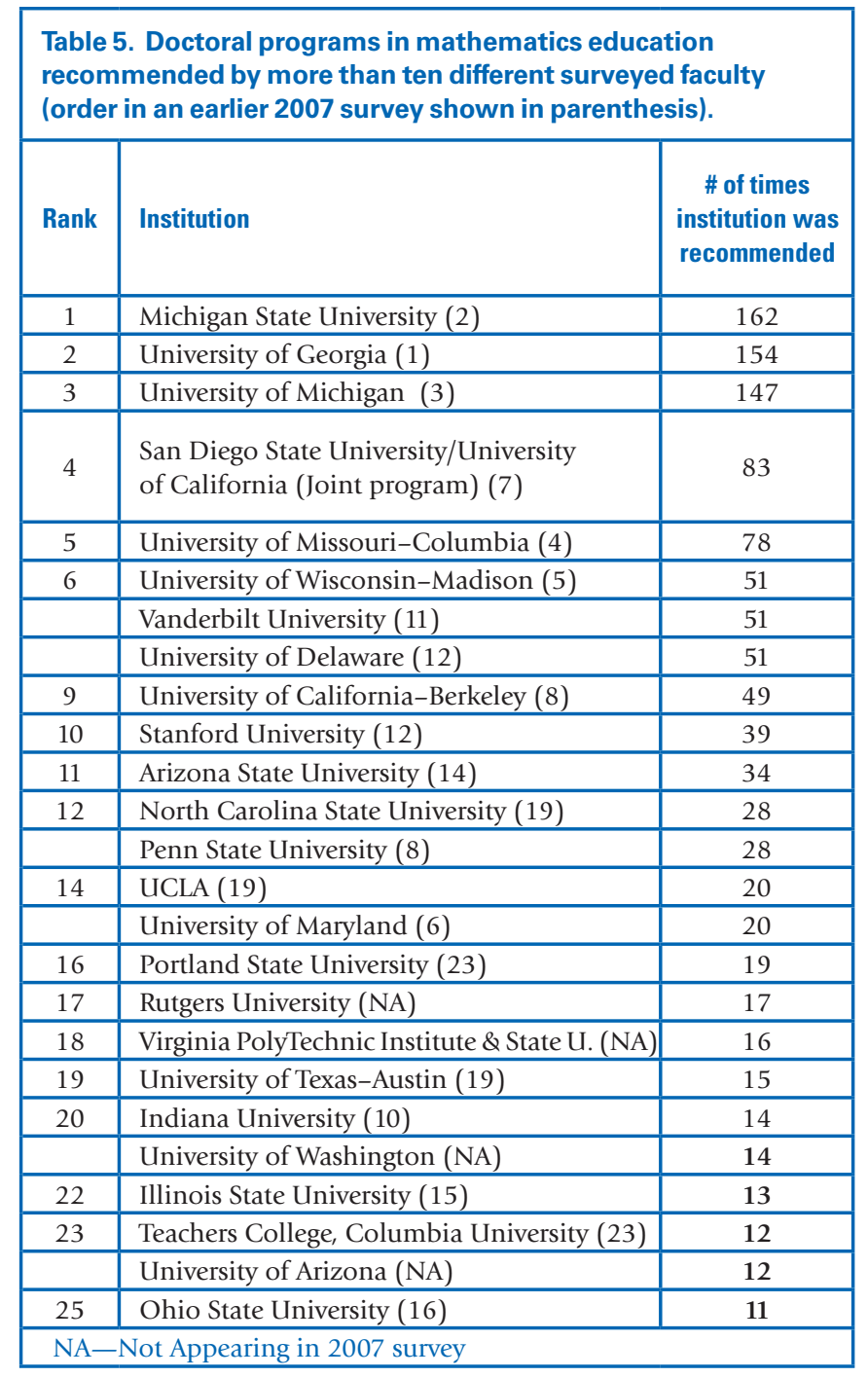

All of the institutions in Table 5, except for the University of Washington and Virginia Tech, are among the programs graduating the most doctorates in mathematics education. Their appearances prompted us to examine their history of producing doctoral graduates. According to the SED data, the University of Washington had a total of three doctorates in mathematics education from 1987 to 2006, yet graduated eight from 2007-2016, so it just fell short of making Table 3. Large growth was also shown by Virginia Tech, changing from 3 to 6 doctoral graduates in mathematics education during the same time periods.

About ten years ago, a list of 'particularly strong doctoral programs in mathematics education' was reported [6]. A comparison of that list with Table 5 shows that seven institutions appear in the top ten of each list, and the first three institutions are the same, except that the University of Georgia and Michigan State University have interchanged. Several institutions not included in the 2007 survey have surfaced in Table 5, including Rutgers University, University of Arizona, University of Washington, and Virginia Tech.

There are some common traits of the institutions shown in Table 5. They each have a core of established and nationally recognized mathematics education faculty members who are engaged in research and scholarly writing as well as active leadership in professional organizations. They have a critical mass of doctoral students and regularly graduate doctorates in mathematics education. Additionally, the faculty at most of these institutions have a record of success in gaining external funds that supports some of their doctoral students.

\section{Summary}

While the list of institutions producing the largest number of doctorates in mathematics education is constantly changing, over one-half of the largest producers during 1987-1996 continued to be among the largest producers in the past two decades. There was a significant growth (nearly 54\%) in the number of new doctoral graduates in mathematics education from 2007-2016 over the previous ten years.

This paper identifies where the faculty members involved in major doctoral programs in mathematics education received their doctorate. This information is important because their experiences as doctoral students will likely shape the direction of future doctoral preparation.

Finally, since there is no accreditation of doctoral programs in mathematics education, it is helpful to potential doctoral students to learn of institutions with doctoral programs in mathematics education that faculty in other doctoral institutions recommend. This peer recognition of doctoral programs in mathematics education can be useful to potential doctoral students in establishing a list of institutions to consider.

\section{References}

[1] Shih J, Reys R, \& Engledowl C, Issues of validity in reporting the number of doctorates in mathematics education, Investigations in Mathematics Learning. 10 (2018), no. 1, $1-8$.

[2] Reys RE, Glasgow R, Ragan GA, and Simms KW, Doctoral programs in mathematics education in the United States: A status report, in R. E. Reys and J. Kilpatrick (eds.), One Field, Many Paths: U.S. Doctoral Programs in Mathematics Education, Washington, D.C.: American Mathematical Society/Mathematical Association of America, 2001, pp. 19-40. 


\section{EDUCATION}

[3] Reys RE, Doctorates in Mathematics Education: An Acute Shortage, Notices Amer. Math. Soc. 47 (2000), no.4, 12671270.

[4] Reys B \& Reys R, A recent history (5 decades) of the production of doctorates in mathematics education, Notices Amer. Math. Soc. 63 (2016), no. 8, 936-939.

[5] Donoghue EF, Mathematics education in the United States: Origins of the field and the development of early graduate programs, in Reys RE and Kilpatrick J (eds.), One Field, Many Paths: U.S. Doctoral Programs in Mathematics Education, American Mathematical Society/Mathematical Association of America, Washington, DC, 2001, pp. 3-18.

[6] Reys R, Glasgow R, Teuscher D, \& Nevels N Doctoral programs in mathematics education in the United States: 2007 Status Report, Notices Amer. Math. Soc. 54(2007), no. $10,1283-1293$.

ACKNOWLEDGMENT. Research for this article was funded by the National Science Foundation under grant No. 1434442. However, the opinions expressed are the authors' and do not reflect any endorsement by the National Science Foundation.

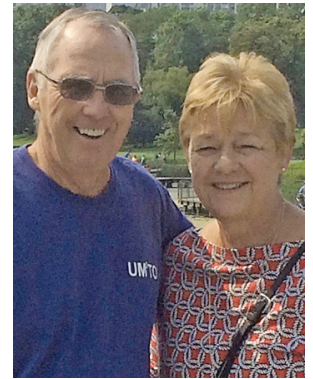

Robert and

Barbara Reys

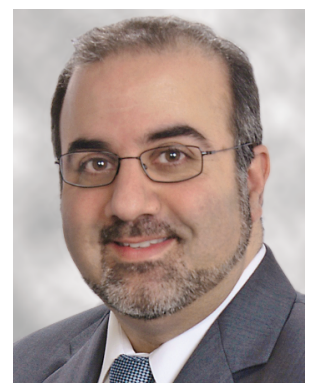

Farshid Safi

Credits

Author photos are courtesy of the authors.
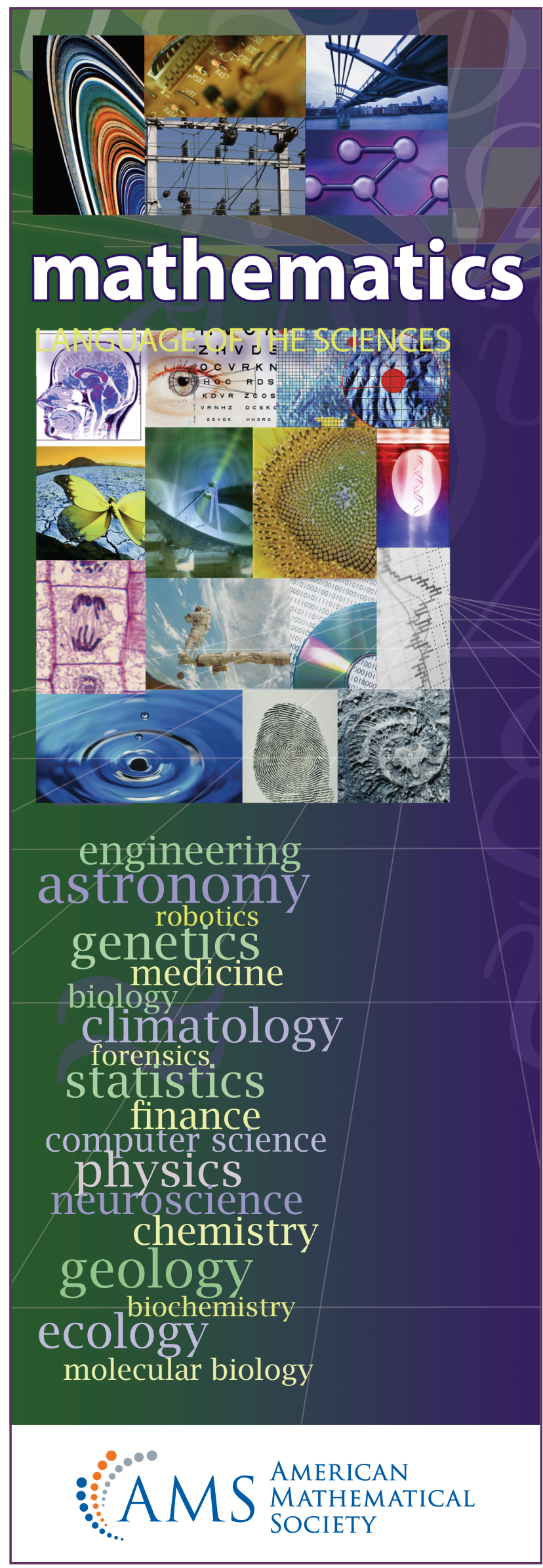